\title{
Low-dose GH improves exercise capacity in adults with GH deficiency: effects of a 22-month placebo-controlled, crossover trial
}

Jens Bollerslev, Jostein Hallén ${ }^{1}$, Kristian J Fougner ${ }^{2}$, Anders Palmstrøm Jørgensen ${ }^{3}$, Cybele Kristo, Hans Fagertun ${ }^{4}$, Ola Gudmundsen ${ }^{5}$, Pia Burman ${ }^{6}$ and Thomas Schreiner ${ }^{3}$

Section of Endocrinology, The National Hospital, Oslo, Norway, ${ }^{1}$ The Norwegian University of Sport and PE, Oslo, Norway ${ }^{2}$ Medical Department, Section of Endocrinology, St Olav's Hospital, Trondheim University Hospital, Trondheim, Norway, ${ }^{3}$ Department of Endocrinology, Aker University Hospital, Oslo, Norway ${ }^{4}$ Capturo AS, Kjeller, Norway ${ }^{5}$ Scandinavian Clinical Research AS, Kjeller, Norway and the ${ }^{6}$ Department of Endocrinology, University Hospital Malmø University Hospital, Malmø, Sweden

(Correspondence should be addressed to J Bollerslev, Section of Endocrinology, Department of Medicine, National University Hospital, N-O027 Oslo, Norway; Email: jens.bollerslev@klinmed.uio.no)

\begin{abstract}
Fifty-five patients with adult-onset GH deficiency (mean age, 49 years) were enrolled in a placebocontrolled, crossover study to investigate the effects of GH therapy on exercise capacity, body composition, and quality of life (QOL). GH and placebo were administered for 9 months each, separated by a 4-month washout period. GH therapy was individually dosed to obtain an IGF-I concentration within the normal range for age and sex. The final mean daily dose of GH was $1.2 \mathrm{IU} /$ day for men and $1.8 \mathrm{IU} /$ day for women. Mean IGF-I concentration at baseline was higher in men than in women $(95 \pm 33$ vs $68 \pm 41 \mu \mathrm{g} / \mathrm{l}$ respectively; $P<0.04)$ and increased to a similar level on GH therapy. Body fat mass was reduced by $1.9 \pm 2.9 \mathrm{~kg}$ and lean body mass was increased by $1.8 \pm 2.8 \mathrm{~kg}$ $(P=0.0001$ for each) with GH treatment. Total and low-density cholesterol levels decreased. Absolute maximal oxygen uptake increased by $6 \%(P=0.01)$, relative to body weight by $9 \%(P=0.004)$, and there was a trend toward increased endurance performance by $7 \%(P=0.07)$. There were no significant effects on QOL. In conclusion, treatment with a low, physiologic dose of GH produced positive effects on body composition and lipids and improved exercise capacity, likely to be of clinical relevance. No changes in QOL were seen, possibly because of a good QOL at baseline.
\end{abstract}

European Journal of Endocrinology 153 379-387

\section{Introduction}

The syndrome of growth hormone deficiency (GHD) is well established, and it encompasses unfavorable changes in body composition and lipid profiles, reduced muscle strength and exercise capacity, and impaired quality of life $(\mathrm{QOL})(1,2)$. Patients with long-standing GHD are less healthy than the normal population (3), and long-term follow-up studies of patients with hypopituitarism have shown reduced life expectancy because of cardiovascular and cerebrovascular disease (4-6). GHD seems to contribute to increased vascular morbidity and mortality rates $(7,8)$; thus, growth hormone (GH) replacement therapy is likely to benefit patients with GHD because it normalizes body composition, improves lipid profiles, and may reduce cardiovascular risk factors (9-13); however, no outcomes studies are available.

GH replacement therapy in adult-onset GHD (AOGHD) increases lean body mass (LBM) (10) and muscle mass $(9,14)$, even at low doses. However, its effect on muscle strength has been controversial. In smaller, relatively short-term studies, GH therapy had no significant effect on muscle strength despite an increase in muscle mass $(14,15)$. In long-term ( $\geq 2$ years), open-label studies, age- and sex-specific increases, and normalization of muscle mass and strength were found with treatment $(16,17)$.

A limited number of placebo-controlled studies have assessed the effect of GH replacement therapy on exercise and endurance capacity (Table 1) $(14,15,18-27)$. In three studies in adults with GHD, a significant increase in endurance capacity (i.e. work performed) was reported with high doses of $\mathrm{GH}(14,23,26)$. In a prospective, open-label study using a lower GH dose (median, $5.0-5.3 \mu \mathrm{g} / \mathrm{kg}$ per day), treatment for 12 months demonstrated a significant improvement in cardiac performance and in exercise endurance capacity (9). To date, no controlled study has investigated the effect of a low, physiologic dose of GH therapy on maximal oxygen uptake ( $\left.\mathrm{vo}_{2} \mathrm{max}\right)$ and endurance capacity in patients with AO-GHD. 
Table 1 Placebo-controlled studies of the effect of recombinant GH therapy on physical exercise.

Author/citation Study design/patients GH dose / duration

\section{Outcome}

Hoffman et al. (18)

Thomas et al. (19)

Rodriguez-Arnao et al. (15)

Vahl et al. (20)

Gullestad et al. (21)

Jorgensen et al. (14)

Johannsson et al. (22)

Nass et al. (23)

Beshyah et al. (24)

Whitehead et al. (25)

Cuneo et al. (26)

Jorgensen et al. (27)
MC, Ran, DB, PC 166 patients with AO-GHD

\section{DB, PC, CX 10 patients}

an, DB, PC 35 patients with GHD (28 with AO-GHD)

Ran DB, PC 27 patients with AO-GHD

\section{DB, PC 20 patients
with CO-GHD}

Ran, DB Parallel 29 patients with AO-GHD

Ran, DB, PC, CX 7 patients with GHD* 21 healthy subjects

DB, PC 20 patients with AO-GHD

Ran, DB PC 40 GHD hypopituitary patients*

DB, PC, CX 14 adults with AO-GHD

DB, PC 24 adults with GHD

Ran, DB, PC, CX 11 adults with MPD 11 adults with IGHD
GH $0.0125 \mathrm{mg} / \mathrm{kg}$ per day increased

to $0.025 \mathrm{mg} / \mathrm{kg}$ per day

or decreased to $0.00625 \mathrm{mg} / \mathrm{kg}$

per day for 12 months

GH $6 \mu \mathrm{g} / \mathrm{kg}$ LBM for 3 months

GH $0.125 \mathrm{IU} / \mathrm{kg}$ per week for 4 weeks followed by $0.25 \mathrm{IU} / \mathrm{kg}$ per week for 6 months (open label)

$\mathrm{GH} 2 \mathrm{IU} / \mathrm{m}^{2}$ per day for 12 months

GH $12 \mu \mathrm{g} / \mathrm{kg}$ per day for 6 months then 36 months (open-label)

GH $2 \mathrm{IU} / \mathrm{m}^{2}$ per day for 12 months

GH $0.5 \mathrm{IU} /$ week for 6 months then 42 months (open label)

$\mathrm{GH} 12.5 \mu \mathrm{g} / \mathrm{kg}$ body weight per day for 6 months

GH $0.04 \mathrm{IU} / \mathrm{kg}$ per day 6 months then 1 months (open-label) 6 months

GH $0.07 \mathrm{IU} / \mathrm{kg}$ body weight daily for 6 months

$\mathrm{GH} 2 \mathrm{IU} / \mathrm{m}^{2}$ per day for 4 months
No significant effect on strength or endurance

(measured by dynamometry for knee extensors)

No additional effect of $\mathrm{GH}$ vs exercise as measured by peak oxygen uptake $\left(\mathrm{VO}_{2}\right.$ peak $)$ and ventilation threshold

No increase on aerobic capacity (measured by an incremental walking test on a treadmill)

Improved exercise capacity

$\left(\mathrm{VO}_{2}\right.$ max measured by bicycle ergometry) was recorded

Exercise capacity increased significantly with GH as assessed by time to exhaustion ( $+0.8 \mathrm{~min})$, total accumulated work $(+11.6 \mathrm{kj})$, and peak

$\mathrm{VO}_{2}(+2.6 \mathrm{ml} / \mathrm{kg}$ per min; $P<0.05$ vs $\mathrm{PC}$ for each)

Significant treatment effect $\mathrm{n}$ exercise capacity,

$11.6 \pm 5.6$ ( $\Delta \mathrm{GH}$ vc $\mathrm{PC} ; P<0.05$ as measured $11.6 \pm 5.6(\Delta \mathrm{GH}$ Vc $P C$; $P$
by ergometer exercise

A beneficial effect on exercise capacity

was observed (measured by computerized bicycle exercise electrocadiography)

Improvement in exercise capacity ( $+35 \mathrm{~W}, P<0.5$ vs $\mathrm{PC})$ measured by bicycle spiroergometer and

$\mathrm{VO}_{2} \max (+68 \mathrm{ml}$ min per kg body weight; $P<0.01 \mathrm{vs} \mathrm{PC}$ )

Exercise time increased significantly at 6,12 and 18 months

Exercise capacity increased significantly

( +25 vs $-8.5 \mathrm{~W} ; P<0.05$ vs $\mathrm{PC})$

as did $\max \mathrm{O}_{2}$ consumption

( $+0.24 \mathrm{vs}+0.06 \mathrm{l} / \mathrm{min} ; P<0.05$ vs $\mathrm{PC}$ )

Improved/normalized maximal exercise performance

( +24.6 vs $+9.7 \mathrm{~W} ; P=0.047$ vs $\mathrm{PC}$ ) (measured by incremental ergometry) and $\mathrm{VO}_{2} \max (+406$ vs

$+133 \mathrm{ml} / \mathrm{min} ; P=0.016 \mathrm{vs} P C$ ) and improved

submaximal exercise performance

Exercise capacity (measured by bicycle exercise)

Exercise capacity (measured by bicycle exercise)
was signtly increase ( 60.8 vs $54.2 \mathrm{~kJ} ; P<0.05$ vs PC)

$\mathrm{CO}-\mathrm{GHD}=$ childhood-onset GH deficiency, $\mathrm{CX}=$ crossover, $\mathrm{DB}=$ double blind, IGHD = isolated GH deficiency, MPD = multiple pituitary deficiencies; $\mathrm{PC}=$ placebo-controlled or placebo

$\mathrm{MC}=$ multicenter, Ran $=$ randomized, $\mathrm{W}=$ watt.

* Not specified whether adult or childhood onset. 
Impaired QOL is of interest as an indication for $\mathrm{GH}$ therapy and the effect of GH treatment may be more pronounced in patients with profound symptoms. Previous studies on the effects of $\mathrm{GH}$ replacement therapy on QOL in patients with AO-GHD have provided inconsistent results (28). This may be related to a number of factors, including the type of QOL questionnaire used, pretreatment conditions, duration of disease, social environment, and the dose of $\mathrm{GH}$ (28). Moreover, in most previous studies, higher doses of $\mathrm{GH}$ were used than are used today, and these studies did not take sex, age, or patient sensitivity to GH into consideration.

The aim of the present study was to investigate the effects and potential benefits of physiologic GH replacement therapy on exercise endurance capacity, muscle strength, $\mathrm{vo}_{2} \max$, body composition, lipid profile, and QOL in GH-naive patients with AO-GHD.

\section{Subjects and methods}

\section{Subjects}

Fifty-five subjects ( 31 men and 24 women; mean age, 49 years (range, 26-62 years)) who had had severe AOGHD for at least 2 years (mean duration, 4.0 (range, $0.3-12.4$ years)) and who had never been treated with GH were randomly assigned to treatment with GH replacement therapy or placebo. Severe GHD was defined as a peak GH response to a stimulation test (insulin tolerance test with a nadir glucose level $\leq 2.2 \mathrm{mmol} / \mathrm{l}$ ) less than $3 \mu \mathrm{g} / \mathrm{l}$. All subjects with multiple pituitary insufficiencies received stable doses of substitution therapy with other hormones for at least 6 months before study entry. Computed tomography or magnetic resonance imaging of the pituitary had been performed within 1 year before the inclusion of each subject in the study.

Primary diagnosis for most subjects $(37 / 55 ; 67 \%)$ was pituitary adenoma; most subjects were treated with surgery alone $(27 / 37 ; 73 \%)$ or with a combination of surgery and irradiation $(7 / 37 ; 19 \%)$. One patient $(1 / 37 ; 3 \%)$ was treated with irradiation only, and the other two patients $(2 / 37 ; 5.4 \%)$ were treated with other therapies. Primary diagnosis was craniopharyngioma $(7 / 55 ; 13 \%)$ or parasellar tumor or meningioma $(3 / 55 ; 5 \%)$ for the other additional subjects; two subjects had cystic tumor of unknown origin. Four subjects acquired hypopituitarism in adulthood from Sheehan syndrome and two subjects had idiopathic hypopituitarism. Of the total study population, most subjects $(53 / 55 ; 96 \%)$ had multiple pituitary deficiencies and only two had isolated GHD. Of the 24 women in the study, 15 underwent estrogen replacement therapy. Six women were considered postmenopausal and did not undergo estrogen replacement therapy, the remaining women were evaluated as eugonadal and no patient received dehydroepiandrosterone. Of the 31 men, 22 received testosterone substitution and the remaining were considered to be eugonadal.

\section{Study design}

Three centers in Norway participated in this prospective, double-blind, randomized, crossover study. An independent ethics committee approved the study protocol, and written informed consent was obtained from all subjects. Subjects underwent treatment with either recombinant human GH therapy (Genotropin; Pfizer Inc, New York, NY, USA) or placebo in a crossover fashion. Each treatment period lasted 9 months, with a 4-month washout interval between periods.

GH replacement therapy was dosed individually to maintain serum insulin-like growth factor-I (IGF-I) concentrations between the mean \pm 1 S.D. of the sexand age-related reference range. GH therapy was initiated at a dose of $0.4 \mathrm{IU} /$ day for men and at $0.8 \mathrm{IU} /$ day for women. Dose adjustments were made in increments of $0.4 \mathrm{IU} /$ day every 4 weeks (maximum dose, 2.0 IU/day (men) and $2.8 \mathrm{IU} /$ day (women)) based on IGF-I concentrations and the absence of adverse effects. A physician who was not blinded to the study and who was not participating in subject care guided all dose adjustments, including dose adjustment for subjects receiving placebo. Patients given placebo received the same adjustments as a given parallel patient receiving active treatment.

At the beginning and end of each treatment period, the following parameters were assessed: exercise capacity, muscle strength, body weight, body composition, physical examination findings, and QOL. Fasting blood samples were obtained and analyzed for IGF-I concentration, glucose, glucosylated hemoglobin (HbA1c) insulin concentrations, and lipid profiles. Adverse effects and vital signs were recorded at each of the monthly visits in each treatment period, including baseline visits (ten visits per treatment period). $\mathrm{vo}_{2} \max$, muscle strength, and QOL tests were performed before baseline (pretest) to familiarize subjects with these procedures.

\section{Physical exercise capacity, muscle strength, and body composition}

Exercise tests and muscle strength were conducted in the subjects from the centers in Oslo, $(n=28$ for $\mathrm{vo}_{2} \max$ and $n=35$ for muscle strength) at a single location by one of the investigators $(\mathrm{J} \mathrm{H})$. $\mathrm{vo}_{2}$ max and time to exhaustion were determined by treadmill walking or running using a stepwise incremental protocol. The exercise test was started at a relatively low intensity to provide a warm-up period; the speed or incline was then increased at 2-min intervals until subjects reached volitional exhaustion. The initial workload was chosen individually according to the pretest, so that the continuous exercizing phase lasted from 8 to $12 \mathrm{~min}$. The work intensity increment was fixed for every subject and was chosen so it equaled approximately 1 metabolic equivalent $(3.5 \mathrm{ml} /(\mathrm{kg} \times \mathrm{min}))$. 
Heart rate (Siemens SC6000; Siemens Nederland N.V., Hague, The Netherlands), ratings of perceived exertion (29), and ergospirometric values (Oxicon; Erich Jaeger $\mathrm{GmbH}$, Hoechberg, Germany) were registered at the last minute before exhaustion. Blood from the fingertip was taken 1 and $3 \mathrm{~min}$ after exhaustion and analyzed for lactate concentrations (YSI 1500 Sport; Yellow Spring Instruments, $\mathrm{OH}$, USA), and the maximal value was registered. Knee extension strength was tested in voluntary isokinetic knee extensions at $60 \%$ using a Cybex 6000 dynamometer (Lumex, Ronkonkoma, NY, USA). The range of motion was set to a knee angle of $90-20^{\circ}$ from full extension. Subjects performed four warm-up contractions followed by three maximal contractions (30). Dominant leg peak torque was used to measure knee extensor muscle strength.

Total body composition was measured by dualenergy X-ray absorptiometry as body fat mass (BFM) and LBM. The two centers in Oslo used Lunar DPX-L, software version 1.31 (Lunar Corp., Madison, WI, USA). The center in Trondheim used the Hologic QDR-4500 (Waltham, MA, USA) in dual-beam mode. Total body imaging was performed and analyzed by one person at each center, as previously described (31).

\section{QOL assessments}

The primary questionnaire was the sum score of the Hopkins Symptom Checklist-58 (HSCL-58) (32). The range of scores possible on the HSCL- 58 questionnaire was 58-232, with low scores indicating better QOL. The generic questionnaire (short form-36 general health survey; SF-36) (33) where higher scores indicate better QOL was also performed. Results of the baseline SF-36 questionnaire were compared with normative Norwegian data (34). Another QOL instrument used was the assessment of growth hormone deficiency in adults (AGHDA) (35).

\section{IGF-I and other chemistry profiles}

Biochemical analyses were performed by accredited laboratories according to standard laboratory methods. IGF-I analysis was performed using the commercial kit Immulite (Diagnostic Products Corporation, Los Angeles, CA, USA). The intra-assay coefficient of variation (C.V.) was $4-8 \%$ and the interassay C.V. was less than 9\%. Insulin, lipids, and other chemistry measurements were performed by routine methods at Furst Laboratory, Oslo, Norway.

\section{Statistical analyses}

An analysis of covariance (ANCOVA) model that included treatment drug, center, baseline value, sex, and age was presented. Variables analyzed with ANCOVA included the sum score for exercise variables (i.e. $\mathrm{VO}_{2} \max (\mathrm{ml} /(\mathrm{kg} \times \mathrm{min})$ and $\mathrm{l} / \mathrm{min})$ endurance time), LBM, BFM, HSCL-58, dimensions of HSCL-58 and SF-36, and sum scores of AGHDA. The difference (month 9 to month 0 ) was the dependent variable in the ANCOVA models. The direct effect of GH therapy compared with placebo treatment was estimated by the crossover effect, which was calculated by taking the difference between $\mathrm{GH}$ and placebo (month 0 to month 9 changes). Using mean values, a point estimate and a two-sided 95\% confidence interval of the crossover differences were calculated. Subjects who withdrew in period 1 were excluded from analysis; those subjects participating for at least 3 months of period 2 were included. All tests performed were two sided, and the significance level was set at $5 \%$.

\section{Results}

\section{Demographics and baseline characteristics of subjects}

Patient demographics and baseline characteristics for the 55 subjects enrolled in the study are summarized in Table 2. Of those subjects enrolled, seven withdrew from the study (two during placebo treatment, three

Table 2 Baseline characteristics of subject with GHD.

\begin{tabular}{|c|c|}
\hline Description & Subjects $(n=55)$ \\
\hline \multicolumn{2}{|l|}{ Sex, $n(\%)$} \\
\hline Men & $31(56.4)$ \\
\hline Women & $24(43.6)$ \\
\hline Mean age, years ( \pm S.D.) & $49(10)$ \\
\hline Mean weight, $\mathrm{kg}( \pm$ S.D.) & $84(20)$ \\
\hline Mean height, $\mathrm{cm}( \pm$ S.D. $)$ & $172(11)$ \\
\hline Mean body mass index ( \pm S.D. $)$ & $28.0(5.0)$ \\
\hline Men & $29.3(4.9)$ \\
\hline Women & $26.4(4.6)$ \\
\hline \multicolumn{2}{|c|}{ HSCL-58 raw scores, mean $( \pm \text { S.D. })^{a}$} \\
\hline All 58 questions & $86.6(25.2)$ \\
\hline Somatization & $1.5(0.5)$ \\
\hline Fearfulness & $1.4(0.5)$ \\
\hline Tension & $1.7(0.6)$ \\
\hline Anxiety & $1.4(0.5)$ \\
\hline Cognition & $1.7(0.6)$ \\
\hline Depression & $1.6(0.5)$ \\
\hline Interpersonal sensitivity & $1.5(0.5)$ \\
\hline Inferiority & $1.3(0.4)$ \\
\hline \multicolumn{2}{|c|}{ SF-36 standardized scores, mean $( \pm \text { S.D. })^{b}$} \\
\hline Physiologic functioning & $84.7(14.6)$ \\
\hline Role physical & $70.7(35.7)$ \\
\hline Bodily pain & $75.3(24.2)$ \\
\hline General health & $65.7(24.8)$ \\
\hline Vitality & $46.9(21.8)$ \\
\hline Social functioning & $81.9(22.3)$ \\
\hline Role emotional & $73.8(34.6)$ \\
\hline Mental health & $76.8(18.4)$ \\
\hline Health transition & $3.0(0.4)$ \\
\hline AGHDA mean ( \pm S.D. & $8.2(6.9)$ \\
\hline
\end{tabular}

AGHDA, mean ( \pm S.D.)

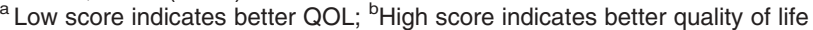
QOL. 
during GH treatment and two withdrew prior to the first study dose). Sufficient data were accumulated in the second treatment period to include one of the two subjects in the analysis of efficacy, resulting in a total of 49 study subjects (29 men and 20 women) who were evaluable for efficacy and safety.

\section{GH doses and IGF-I levels}

Fig. 1 illustrates IGF-I concentrations at baseline compared with age-adjusted IGF-I reference curves. Mean baseline IGF-I concentrations were significantly higher in men $(95 \pm 33$ vs $68 \pm 41 \mu \mathrm{g} / \mathrm{l}$ respectively; $P<0.04)$. Mean final dose of $\mathrm{GH}$ in women $(1.8 \pm 0.8 \mathrm{IU} /$ day $)$ was approximately $50 \%$ greater than the dose used in men $(1.2 \pm 0.6 \mathrm{IU} /$ day; $P=$ 0.03). Women prescribed estrogen replacement therapy $(n=15)$ tended to require higher doses of $\mathrm{GH}$ than women not prescribed estrogen $(n=9)(2.0 \pm 0.9$ vs $1.6 \pm 0.3 \mathrm{IU} /$ day; $P<0.05)$. The mean time to reach the final GH dose was 3.2 months. During treatment with GH, IGF-I concentrations increased to a similar level in men and women $(217 \pm 65$ and $186 \pm 70 \mu \mathrm{g} / \mathrm{l}$

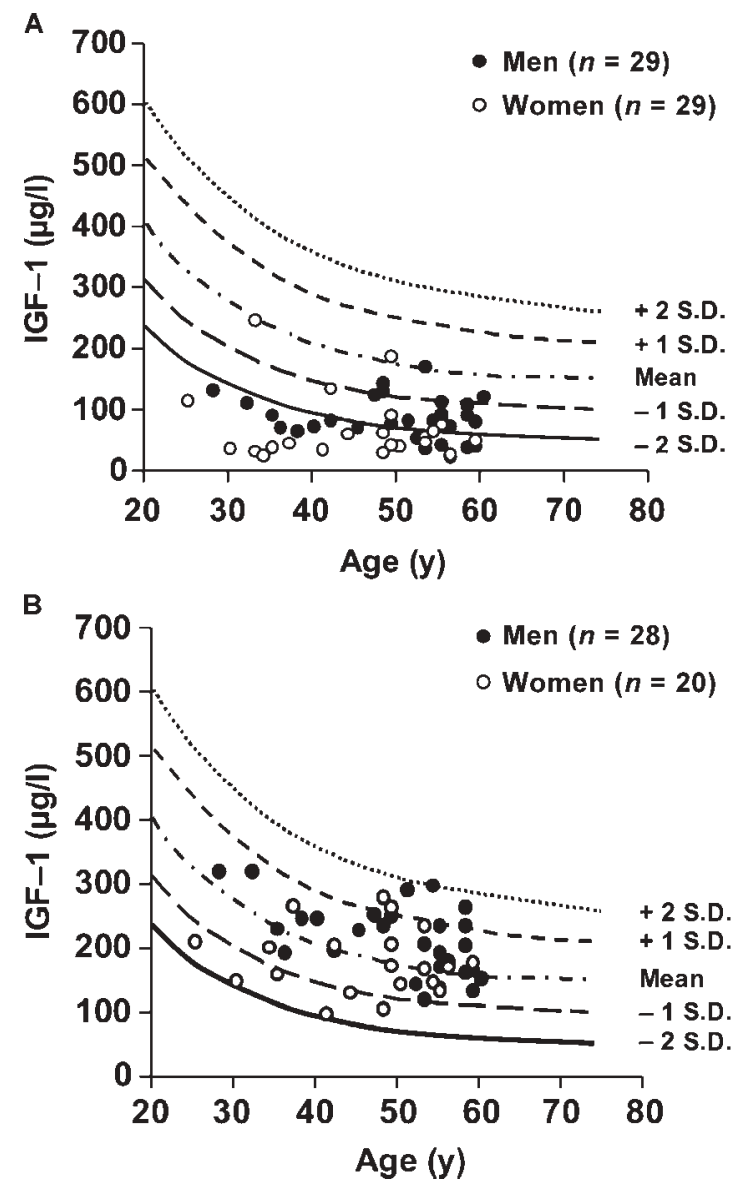

Figure 1 IGF-I concentrations (A) according to sex at baseline and $(B)$ after last dose titration of GH therapy. respectively; $\mathrm{P}=$ not significant (NS); Fig. 1). In two women the final dose of $\mathrm{GH}$ administered did not increase IGF-I to the desired level.

\section{Exercise capacity and leg muscle strength}

$\mathrm{vo}_{2}$ max increased significantly with $\mathrm{GH}$ treatment compared with placebo in absolute value (l/min, $6 \%$; $P=0.01)$ and relative to body weight $(\mathrm{ml} /(\mathrm{kg} \times \mathrm{min})$, $9 \% ; P=0.004$ ) (Fig. 2). The crossover difference for endurance performance increased by $0.6 \mathrm{~min}$ in favor of $\mathrm{GH}$ treatment, representing a $7 \%$ increase $(P=0.07)$. Heart rate, ventilation rate, respiratory exchange ratio, rating of perceived exertion, and lactate concentration at exhaustion were not significantly different between the treatment periods (data not shown). Knee extensor peak torque was $178.5 \pm 62.8$
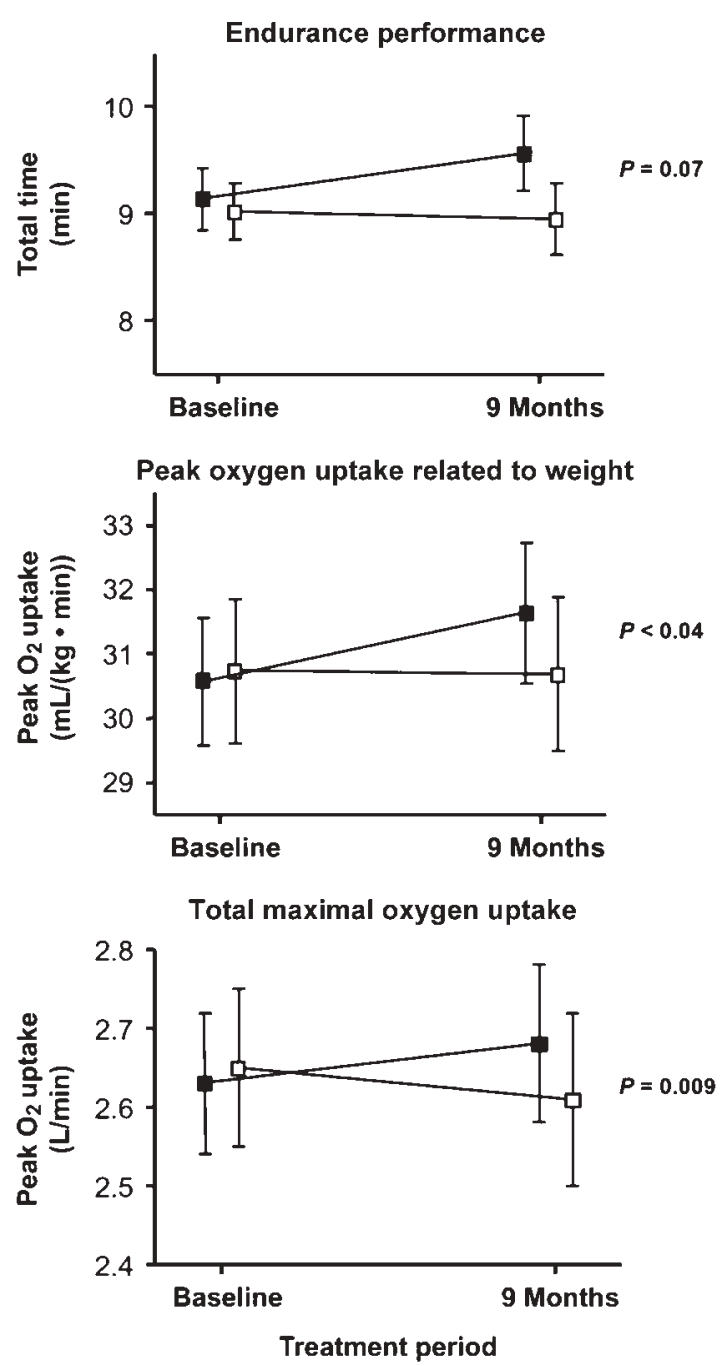

Figure 2 Effect of GH therapy ( $\square$ ) and placebo ( $\square$ ) on exercise capacity. 
Newton meters $(\mathrm{Nm})$ before and 176.3 $\pm 62.0 \mathrm{Nm}$ after $\mathrm{GH}$ treatment $(P=\mathrm{NS})$.

\section{Body composition and lipid profile}

LBM increased with GH replacement therapy compared with placebo $(1.8 \pm 2.8 \mathrm{~kg} ; P=0.0001)$ and BFM decreased significantly $(1.9 \pm 2.9 \mathrm{~kg} ; \quad P=0.0001)$. Total and low-density lipoprotein cholesterol concentrations decreased by $0.50 \mathrm{mmol} / \mathrm{l}(P=0.004)$ and $0.47 \mathrm{mmol} / \mathrm{l}(P=0.0002)$ respectively, whereas triglycerides increased by $0.40 \mathrm{mmol} / \mathrm{l}(P=0.01)$ during GH treatment.

\section{QOL assessments}

QOL was not impaired in most subjects, as is represented by the mean baseline values as assessed by the HSCL-58, the SF-36, and the AGHDA in Table 2. After 9 months of GH treatment, overall QOL in subjects was not significantly different from the reported QOL in those receiving placebo. There was no sex difference in response to treatment. Assessment in patients with HSCL-58 values above the median sum score of 78 showed that there was a marked improvement in women compared with men with respect to the global score $(P=0.033)$ and in dimensions assessing somatization $(P=0.026)$, fearfulness $(P=0.003)$, and tension $(P=0.016)$. Figure 3 compares baseline SF-36 results of study patients with those of normative Norwegian data (34). Patients with AO-GHD scored lower than the referenced healthy population only in the sum scores vitality and general health.

\section{Safety}

During active treatment, serum insulin concentrations increased by $33.7 \mathrm{pmol} / \mathrm{l}(P<0.02)$, fasting glucose concentrations increased by $0.49 \mathrm{mmol} / \mathrm{l}(P=0.02)$, and $\mathrm{HbAlc}$ increased by $0.14 \%(P=0.05)$. There were no differences in the effect of treatment between women and men. Numbers of adverse effects, changes in vital signs, and physical examination findings were similar in both treatment periods.

\section{Discussion}

In the present study, a low physiologic dose of GH was associated with improvements in body composition, low-density lipoprotein cholesterol, and exercise capacity. Glucose levels were moderately increased within the normal range. The effects of GH therapy on lipids and glucose metabolism were in accordance with previous studies in patients with GHD (36), which in general have used higher doses of GH. The effect on body composition in the present study was less prominent compared with the observed changes with higher doses of $\mathrm{GH}(27,37,38)$, a finding that corroborates the work by De Boer et al. (39), in which effects on adiposity were found to be dose dependent.

Previous studies assessing the effects of GH therapy on exercise capacity in patients with GHD have been open labeled $(9,40-44)$ or have used higher, weightbased or fixed doses of GH $(14,15,18,20-23,25$, 26). In the present study, we attempted to reduce a possible placebo effect by using a similar individualized GH dosing regimen during each treatment period. The dose of GH was lower than used in previous controlled studies and took into account the sex-related difference in $\mathrm{GH}$ responsiveness in women by using a higher starting dose and allowing for a higher final dose. Using this method, we found that women treated with GH needed a dose approximately 50\% greater than that administered to men to obtain the target

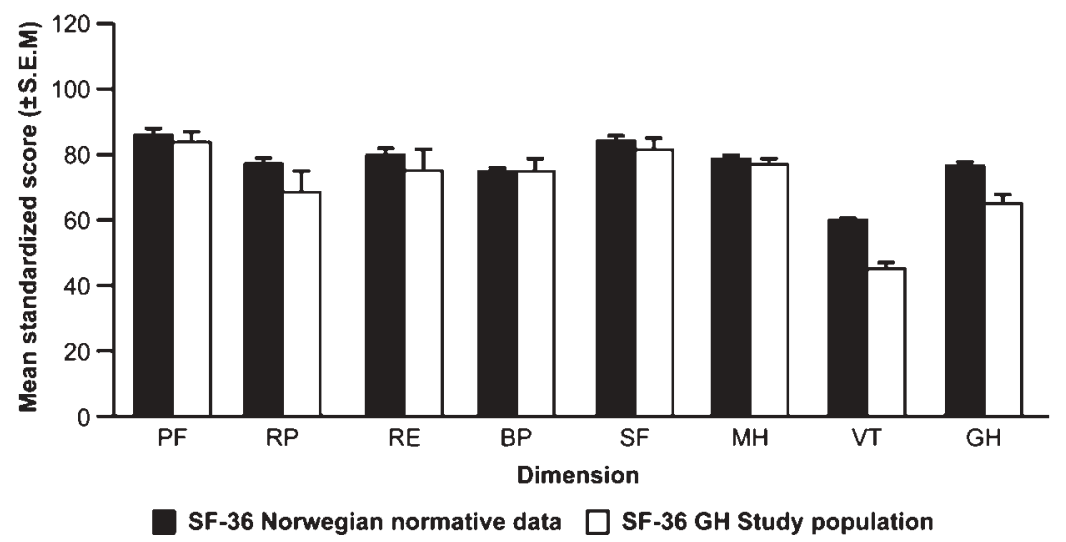

Figure 3 SF-36 general health survey baseline results ( \pm S.E.M.) of study population ( $\square$ ) compared with healthy Norwegian subjects ( $\square$ ) (30). The short form dimensions are shown. PF, physical functioning; RP, role physical; RE, role emotional; BP, bodily pain; SF, social functioning; $\mathrm{MH}$, mental health; VT, vitality; $\mathrm{GH}$, general health. 
IGF-I concentration and similar effects on body composition and lipids.

In studies of patients with GHD $(41,44,45)$, GH treatment with higher doses has been associated with increases of up to $20 \%$ in exercise performance. An increase in $\mathrm{vO}_{2} \max$ of $7-9 \%$ as found in this study is likely to be clinically relevant in middle-aged patients, improving daily exercise capacity (46). Physical training per se, in the absence of GHD, typically increases $\mathrm{vo}_{2} \max$ by $10-20 \%$, depending on training status and genetic predisposition (46).

The improvement in endurance capacity was paralleled by a similar increase in absolute and relative $\mathrm{vo}_{2} \max$. Theoretically, the increase in oxygen uptake could be explained, in part, by alterations in LBM. However, adjusting for the change in LBM did not change the results (data not shown), indicating that additional factors are likely to contribute, for instance, an increase in cardiac output $(41,44)$. Interestingly, physical capacity, as measured in our cohort at baseline, was not correlated with IGF-I concentrations but with baseline QOL (data not shown). Recently, in a controlled study, the potential benefit of combining an exercise program with GH replacement therapy for 3 months in ten patients with GHD was studied (19). A positive effect of training was noted, but no additive effect of GH therapy was observed, illustrating that physical fitness may influence the extent of change achieved by GH. In our study, we did not find a relation between the baseline exercise capacity and the response to GH.

Muscle strength was not improved by active treatment in this study in accordance with other investigations using $\mathrm{GH}$ in physiologic doses $(14,15)$, although some positive effect has been reported in two long-term, open-label studies $(16,17)$. The lack of effect in the present study is not surprising, even if muscle mass was greater (LBM, $1.8 \mathrm{~kg}$ ) during $\mathrm{GH}$ therapy than with placebo because muscle strength is determined by several factors, in addition to muscle size (16). It is likely that GH therapy alone, without an adequate weight-training program, is not sufficient to produce an increase in muscle strength (15).

QOL was assessed by a variety of non-specific and disease-specific questionnaires in this study. In contrast to findings in several previous controlled and open-label studies $(3,47,48)$, we were unable to demonstrate significant improvements in QOL. Several explanations are possible. Because GH has been in clinical use for several years, our population might have represented a population of patients with slight or vague symptoms (49). This is suggested by the results of the SF- 36 questionnaire. Patients scored lower, but not significantly lower, for each of the separate domains compared with normative data. Only the sum scores vitality and general health were significantly reduced, substantiating the minor reduction in psychologic health in our population at baseline. In addition to patient selection, the benefit of GH therapy on QOL in early studies might have been related to higher GH dosing, either throughout the studies or during the initial phases (49).

In conclusion, physiologic and individualized $\mathrm{GH}$ replacement therapy aimed at normalizing IGF-I concentration in relation to age in $\mathrm{GH}$-naive patients with AO-GHD was followed by significant improvements in body composition, as well as low-density lipoprotein cholesterol and exercise capacity. Treatment with $\mathrm{GH}$ was not associated with changes in the patients' perceived QOL, probably because these patients had a good QOL at the onset of the study.

\section{Acknowledgements}

At the time that the clinical study was completed, P B was an employee in the Department of Endocrine Care for Pfizer Inc., New York, NY, USA. This study was supported by Pfizer Inc., New York, NY, USA.

\section{References}

1 Carroll PV, Christ ER, Bengtsson BA, Carlsson L, Christiansen JS, Clemmons D, Hintz R, Ho K, Laron Z, Sizonenko P, Sonksen PH, Tanaka T \& Thorne M. Growth hormone deficiency in adulthood and the effects of growth hormone replacement: a review. Growth Hormone Research Society Scientific Committee. Journal of Clinical Endocrinology and Metabolism $1998 \mathbf{8 3} 382-395$.

2 De Boer H, Blok GJ \& Van Der Veen EA. Clinical aspects of growth hormone deficiency in adults. Endocrine Reviews 199516 63-86.

3 Hernberg-Stahl E, Luger A, Abs R, Bengtsson BA, FeldtRasmussen U, Wilton P, Westberg B \& Monson JP. Healthcare consumption decreases in parallel with improvements in quality of life during $\mathrm{GH}$ replacement in hypopituitary adults with $\mathrm{GH}$ deficiency. Journal of Clinical Endocrinology and Metabolism 2001 $865277-5281$.

4 Rosen T \& Bengtsson BA. Premature mortality due to cardiovascular disease in hypopituitarism. Lancet 1990336 285-288.

5 Bulow B, Hagmar L, Mikoczy Z, Nordstrom CH \& Erfurth EM. Increased cerebrovascular mortality in patients with hypopituitarism. Clinical Endocrinology $1997 \mathbf{4 6} 75-81$.

6 Tomlinson JW, Holden N, Hills RK, Wheatley K, Clayton RN, Bates AS, Sheppard MC \& Stewart PM. Association between premature mortality and hypopituitarism. West Midlands Prospective Hypopituitary Study Group. Lancet 2001357 425-431.

7 Rosen T, Wilhelmsen L \& Bengtsson B-A. Altered lipid pattern explains increased cardiovascular mortality in hypopituitary patients with growth hormone deficiency (letter). Clinical Endocrinology $1998 \mathbf{4 8} 525-526$.

8 Svensson J, Bengtsson BA, Rosen T, Oden A \& Johannsson G. Malignant disease and cardiovascular morbidity in hypopituitary adults with or without growth hormone replacement therapy. Journal of Clinical Endocrinology and Metabolism $2004893306-3312$.

9 Colao A, Di Somma C, Pivonello R, Cuocolo A, Spinelli L, Bonaduce D, Salvatore M \& Lombardi G. The cardiovascular risk of adult GH deficiency (GHD) improved after GH replacement and worsened in untreated GHD: a 12-month prospective study. Journal of Clinical Endocrinology and Metabolism 2002 87 1088-1093.

10 Abrahamsen B, Nielsen TL, Hangaard J, Gregersen G, Vahl N, Korsholm L, Hansen TB, Andersen M \& Hagen C. Dose-IGF-Iand sex-dependent changes in lipid profile and body composition during GH replacement therapy in adult onset GH deficiency. European Journal of Endocrinology $2004150671-679$.

11 Sesmilo G, Biller BM, Llevadot J, Hayden D, Hanson G, Rifai N \& Klibanski A. Effects of growth hormone $(\mathrm{GH})$ administration on homocyst(e)ine levels in men with GH deficiency: a randomized 
controlled trial. Journal of Clinical Endocrinology and Metabolism $2001861518-1524$.

12 Pfeifer M, Verhovec R, Zizek B, Prezelj J, Poredos P \& Clayton RN. Growth hormone $(\mathrm{GH})$ treatment reverses early atherosclerotic changes in GH-deficient adults. Journal of Clinical Endocrinology and Metabolism 199984 453-457.

13 Borson-Chazot F, Serusclat A, Kalfallah Y, Ducottet X, Sassolas G, Bernard S, Labrousse F, Pastene J, Sassolas A, Roux Y \& Berthezene F. Decrease in carotid intima-media thickness after one year growth hormone (GH) treatment in adults with $\mathrm{GH}$ deficiency. Journal of Clinical Endocrinology and Metabolism 1999 84 1329-1333.

14 Jorgensen JO, Vahl N, Hansen TB, Thuesen L, Hagen C \& Christiansen JS. Growth hormone versus placebo treatment for one year in growth hormone deficient adults: increase in exercise capacity and normalization of body composition. Clinical Endocrinology $199645681-688$.

15 Rodriguez-Arnao J, Jabbar A, Fulcher K, Besser GM \& Ross RJ. Effects of growth hormone replacement on physical performance and body composition in GH deficient adults. Clinical Endocrinology $19995153-60$.

16 Johannsson G, Grimby G, Sunnerhagen KS \& Bengtsson BA. Two years of growth hormone $(\mathrm{GH})$ treatment increase isometric and isokinetic muscle strength in GH-deficient adults. Journal of Clinical Endocrinology and Metabolism 199782 2877-2884.

17 Svensson J, Stibrant SK \& Johannsson G. Five years of growth hormone replacement therapy in adults: age- and genderrelated changes in isometric and isokinetic muscle strength. Journal of Clinical Endocrinology and Metabolism $2003 \mathbf{8 8}$ 2061-2069.

18 Hoffman AR, Kuntze JE, Baptista J, Baum HB, Baumann GP, Biller BM, Clark RV, Cook D, Inzucchi SE, Kleinberg D, Klibanski A, Phillips LS, Ridgway EC, Robbins RJ, Schlechte J, Sharma M, Thorner MO \& Vance ML. Growth hormone (GH) replacement therapy in adult-onset GH deficiency: effects on body composition in men and women in a double-blind, randomized, placebo-controlled trial. Journal of Clinical Endocrinology and Metabolism $2004892048-2056$.

19 Thomas SG, Esposito JG \& Ezzat S. Exercise training benefits growth hormone (GH)-deficient adults in the absence or presence of GH treatment. Journal of Clinical Endocrinology and Metabolism $2003885734-5738$.

20 Vahl N, Jorgensen JO, Hansen TB, Klausen IB, Jurik AG, Hagen C \& Christiansen JS. The favourable effects of growth hormone (GH) substitution on hypercholesterolaemia in $\mathrm{GH}$-deficient adults are not associated with concomitant reductions in adiposity. A 12 month placebo-controlled study. International Journal of Obesity and Related Metabolic Disorders 199822 529-536.

21 Gullestad L, Birkeland K, Bjonerheim R, Djoseland O, Trygstad O \& Simonsen S. Exercise capacity and hormonal response in adults with childhood onset growth hormone deficiency during longterm somatropin treatment. Growth Hormone and IGF Research $19988377-384$.

22 Johannsson G, Bengtsson BA, Andersson B, Isgaard J \& Caidahl K. Long-term cardiovascular effects of growth hormone treatment in GH-deficient adults. Preliminary data in a small group of patients Clinical Endocrinology 199645 305-314.

23 Nass R, Huber RM, Klauss V, Muller OA, Schopohl J \& Strasburger CJ. Effect of growth hormone (hGH) replacement therapy on physical work capacity and cardiac and pulmonary function in patients with hGH deficiency acquired in adulthood. Journal of Clinical Endocrinology and Metabolism $1996 \mathbf{8 0}$ $552-557$.

24 Beshyah SA, Freemantle C, Shahi M, Anyaoku V, Merson S, Lynch S, Skinner E, Sharp P, Foale R \& Johnston DG. Replacement treatment with biosynthetic human growth hormone in growth hormone-deficient hypopituitary adults. Clinical Endocrinology $19954273-84$.

25 Whitehead HM, Boreham C, McIlrath EM, Sheridan B, Kennedy L, Atkinson AB \& Hadden DR. Growth hormone treatment of adults with growth hormone deficiency: results of a 13-month placebo controlled cross-over study. Clinical Endocrinology $1992 \mathbf{3 6}$ $45-52$.

26 Cuneo RC, Salomon F, Wiles CM, Hesp R \& Sonksen PH. Growth hormone treatment in growth hormone-deficient adults II. Effects on exercise performance. Journal of Applied Physiology $1991 \mathbf{7 0}$ $695-700$.

27 Jorgensen JO, Pedersen SA, Thuesen L, Jorgensen J, IngemannHansen T, Skakkebaek NE \& Christiansen JS. Beneficial effects of growth hormone treatment in GH-deficient adults. Lancet 1989 i $1221-1225$.

28 Burman P \& Deijen JB. Quality of life and cognitive function in patients with pituitary insufficiency. Psychotherapy and Psychosomatics 199867 154-167.

29 Borg GA. Psychophysical bases of perceived exertion. Medicine and Science in Sports and Exercise 198214 377-381.

30 Raastad T \& Hallen J. Recovery of skeletal muscle contractility after high- and moderate-intensity strength exercise. European Journal of Applied Physiology 200082 206-214.

31 Godang K, Ueland T \& Bollerslev J. Decreased bone area, bone mineral content, formative markers, and increased bone resorptive markers in endogenous Cushing's syndrome. European Journal of Endocrinology 1999141 126-131.

32 Derogatis LR, Lipman RS, Rickels K, Uhlenhuth EH \& Covi L. The Hopkins Symptom Checklist (HSCL): a self-report symptom inventory. Behavioral Science 197419 1-15.

33 Jenkinson C, Coulter A \& Wright L. Short form 36 (SF36) health survey questionnaire: normative data for adults of working age. British Medical Journal 1993306 1437-1440.

34 Loge JH \& Kaasa S. Short form 36 (SF-36) health survey: normative data from the general Norwegian population. Scandinavian Journal of Social Medicine 199826 250-258.

35 McKenna SP, Doward LC, Alonso J, Kohlmann T, Niero M, Prieto L \& Wiren L. The QoL-AGHDA: an instrument for the assessment of quality of life in adults with growth hormone deficiency. Quality of Life Research 19998 373-383.

36 Maison P, Griffin S, Nicoue-Beglah M, Haddad N, Balkau B \& Chanson P. Impact of growth hormone $(\mathrm{GH})$ treatment on cardiovascular risk factors in GH-deficient adults: a meta-analysis of blinded, randomized, placebo-controlled trials. Journal of Clinical Endocrinology and Metabolism $2004892192-2199$.

37 Salomon F, Cuneo RC, Hesp R \& Sonksen PH. The effects of treatment with recombinant human growth hormone on body composition and metabolism in adults with growth hormone deficiency. New England Journal of Medicine 1989321 1797-1803.

38 Bengtsson BA, Eden S, Lonn L, Kvist H, Stokland A, Lindstedt G, Bosaeus I, Tolli J, Sjostrom L \& Isaksson OG. Treatment of adults with growth hormone (GH) deficiency with recombinant human GH. Journal of Clinical Endocrinology and Metabolism $1993 \mathbf{7 6}$ $309-317$.

39 De Boer H, Blok GJ, Voerman B, Derriks P \& van der Veen E. Changes in subcutaneous and visceral fat mass during growth hormone replacement therapy in adult men. International Journal of Obesity and Related Metabolic Disorders 199620 580-587.

40 Jallad RS, Liberman B, Vianna CB, Vieira ML, Ramires JA \& Knoepfelmacher M. Effects of growth hormone replacement therapy on metabolic and cardiac parameters, in adult patients with childhood-onset growth hormone deficiency. Growth Hormone and IGF Research 200313 81-88.

41 Colao A, Di Somma C, Cuocolo A, Spinelli L, Tedesco N, Pivonello R, Bonaduce D, Salvatore M \& Lombardi G. Improved cardiovascular risk factors and cardiac performance after 12 months of growth hormone $(\mathrm{GH})$ replacement in young adult patients with GH deficiency. Journal of Clinical Endocrinology and Metabolism 200186 1874-1881.

42 Orme SM, Sebastian JP, Oldroyd B, Stewart SP, Grant PJ, Stickland MH, Smith MA \& Belchetz PE. Comparison of measures of body composition in a trial of low dose growth hormone replacement therapy. Clinical Endocrinology 199237 453-459. 
43 Chrisoulidou A, Beshyah SA, Rutherford O, Spinks TJ, Mayet J, Kyd P, Anyaoku V, Haida A, Ariff B, Murphy M, Thomas E, Robinson S, Foale R \& Johnston DG. Effects of 7 years of growth hormone replacement therapy in hypopituitary adults. Journal of Clinical Endocrinology and Metabolism $2000 \mathbf{8 5}$ $3762-3769$.

44 ter Maaten JC, De Boer H, Kamp O, Stuurman L \& Van Der Veen EA. Long-term effects of growth hormone (GH) replacement in men with childhood-onset GH deficiency. Journal of Clinical Endocrinology and Metabolism $1999842373-2380$.

45 Jorgensen JO, Thuesen L, Muller J, Ovesen P, Skakkebaek NE \& Christiansen JS. Three years of growth hormone treatment in growth hormone-deficient adults: near normalization of body composition and physical performance. European Journal of Endocrinology $1994130224-228$.

46 Skinner JS, Gaskill SE, Rankinen T, Leon AS, Rao DC, Wilmore JH \& Bouchard C. Heart rate versus $\% \mathrm{vo}_{2} \max$ : age, sex, race, initialfitness, and training response:HERITAGE. Medicine and Science in Sports and Exercise $2003351908-1913$.
47 Burman P, Broman JE, Hetta J, Wiklund I, Erfurth EM, Hagg E \& Karlsson FA. Quality of life in adults with growth hormone (GH) deficiency: response to treatment with recombinant human GH in a placebo-controlled 21-month trial. Journal of Clinical Endocrinology and Metabolism 199580 3585-3590.

48 Ahmad AM, Hopkins MT, Thomas J. Ibrahim H, Fraser WD \& Vora JP. Body composition and quality of life in adults with growth hormone deficiency; effects of low-dose growth hormone replacement. Clinical Endocrinology 200154 709-717.

49 Murray RD \& Shalet SM. Adult growth hormone replacement: lessons learned and future direction. Journal of Clinical Endocrinology and Metabolism 200287 4427-4428.

Received 23 March 2005

Accepted 25 May 2005 